\title{
EFFECTS OF DIFFERENT STIRRING RATES ON THE CHLORELLA VULGARIS GROWTH FOR WASTEWATER TREATMENT SYSTEMS
}

\author{
Dabai Aminu Isiya \\ Department of Civil Engineering Technology, \\ Federal Polytechnic, Kaura Namoda, Nigeria
}

\begin{abstract}
Microalgae were found to be suitable for wastewater bioremediation. Certain parameters are capable to influence their growth, in which stirring was among these factors. In this research, three MSTPBRs $R_{1}, R_{2}$ and $R_{3}$, were fabricated and set at average stirring rates 50, 100 and 120rpm to assessed impact of various stirring rate for Chlorella vulgaris specie growth. After 21days of inoculation at optimum irradiance of $582.7 \mu \mathrm{mol} / \mathrm{m}^{2} \mathrm{~s}$, pH of 7.1 and using MBBM, the highest biomass concentration of 195 was obtained in $\mathbf{R 2}$ with 100rpm stirring rate with a corresponding estimated biomass growth rate of $0.72 d^{-1}$
\end{abstract}

Keywords; microalgae, aeration, stirring rates, biomass concentration, growth, MSTPBR

\section{INTRODUCTION}

Microalgae are considered to be the best option in wastewater treatment systems due to their ability to grow in different and varying strength of wastewater, utilizes light and carbon-dioxide $\left(\mathrm{CO}_{2}\right)$, assimilate nutrients present in the wastewater, uptake heavy metals ions in contaminated effluent solutions and provision of the renewable energy alternatives such as biodiesel, biogas, biofuels and other valuable extracts with numerous industrial applications

In order to achieve this, several biotic and abiotic factors need to be optimized to tap all the benefits associated with this novel treatment approach. These factors include light, $\mathrm{pH}$, oxygen $\left(\mathrm{O}_{2}\right), \mathrm{CO}_{2}$, temperature, salinity, competition among species, dilution rate, mixing, depth, frequency of the harvesting, extracellular secretion of inhibitory substances and gas diffusion may all influence the success of algal wastewater treatment system (Agarwal et al., 2019) and above all, Pedruzi et al., (2020) ascertain that stirring (in other ward

\author{
Magaji Sani \\ Department of Civil Engineering Technology, \\ Federal Polytechnic, Kaura Namoda, Nigeria
}

mechanical agitation) and aeration affects all the mentioned factors.

\begin{abstract}
Mixing and aeration are significant parameters in biotechnology for wastewater and industrial effluent treatment as it facilitates organic matter degradation, that influence the respiration of microorganisms, promote $\mathrm{CO}_{2}$ availability, provide efficient nutrients circulation, increases gaseous mass transfer rate, mitigation of stratification formation, light limitation and photoinhibition (Agarwal et al., 2019; Mohammed et al., 2014a; Pedruzi et al., 2020)
\end{abstract}

Some credits were associated with the provision of efficient mixing such as uniform exposure of cells to the light source(s), enhancing the uptake of $\mathrm{CO}_{2}$, and releasing, thereby reducing the rate of greenhouse gases emissions and guarding against global warming (García et al., 2017). Xie et al., (2017) reported that for algal cultivation, mixing not only beneficial to the $\mathrm{CO}_{2}$ mass transfer but settling prevention as well as homogeneous mixed condition maintenance of the suspended algal cells (de la Noue et al., 1984) and also cell wall destruction and introduction of modified DNA to the cells were achieved through agitation in presence of glass beads (Fu and Wang, 2011)

Stirring play vital role in maintenance of cell suspension to mitigate gradient zone stratification, nutrients distribution and enhances gas exchange (Pedruzi et al., 2020). It also eliminate problems associated with provision of light like light limitation by self-shading as well as photoinhibition (Mohammed et al., 2014b). Open systems such as raceways were associated with paddle wheel to achieve a thorough mixing (Pathak et al., 2019; Priyadarshani et al., 2014) while in a closed systems, the parameters like gas transfer, mixing and lighting were more controlled 
systematically than the open systems and achieve higher treatment efficiencies.

In the aerated systems, air is introduced to the culture usually by the a pump connected with small diameter tubes (Komolafe et al., 2013) at the bottom of the reactor or container to allow mixing to prevent sedimentation, increases gas exchange and evenly distributed media, while mechanical agitation was usually provided by connecting electrical motors with stirrer shaft rotating the starring blade or impeller. Mohammed et al., (2014a) achieved stirring through the use of overhead mechanical stirrer centrally provided at about $100 \pm$ rpm.

The rate of growth for photosynthetic microorganisms increases with an increment of agitation until an optimum stirring rate was attained which is specie dependant (Sobczuk et al., 2006) and beyond this, a sharp decrease in growth was noticed as a result of higher turbulence that damage the cells as some algal species have fragile cell wall, filamentous or mobile that can be susceptible to physical stress (Sobczuk et al., 2006). Thus, a minimum possible required stirring rate should be provided in order to promote the biomass growth and subsequent extraction of valuable materials from it (Pedruzi et al., 2020)

Some researchers tried to differentiate the impact of aeration by the use of pumps and agitation by mechanical stirrer. Benítez et al., (2018) reported that a relatively higher ammonium removal efficiency was achieved in aerated than in agitated culture by microalgal specie in PBRs, while a much greater phosphate was removed through agitation and aeration. A complete nitrification process was attained in the absence of aeration as reported by some researchers to support the idea of stirring is more important than aeration in a treatment system

Priyadarshani et al., (2014) shows an increase in the growth rate and corresponding protein content in cultures supplied with aeration than those without aeration and also a proportional increase in biomass growth was reported with increment of mechanical stirring up to the optimum stirring rate and beyond that, a decrease in biomass concentration is observed due to damage of cells as a result of rapture by high gas bubbles at culture surface (Sobczuk et al., 2006) and this problem is specie dependant especially those lacking rigid cell walls. Contrarily, Mustafa et al., (2019) ascertained that agitation hinders the growth of L casai grown in pomegranate juice and biomass growth, lactic acid and cell viability was decreased as stirring rate increases from 0-150rpm.
However, considering the value of stirring in the biomass growth and productivity in microalgal wastewater treatment approach with consequent extraction of valuable renewable energy alternatives with contrary arguments of effects stirring rates to some particular biomass species, a thorough investigation of the impact of stirring and aeration will be needed in order to explore the highest benefit and selected the most promising algal strain for this purpose. Pedruzi et al., (2020) strongly recommended that, the factors that influence the growth of microalgae should be thoroughly investigated and optimized in order to achieve a maximum biomass productivity that enhances the removal efficiencies of nutrients, heavy metals and other pollutants as well as increased extraction of biofuels at cost-effective and sustainable way

Based on the above, this research was intended to use the Modified Bold Basal Media (MBBM) composition reported by Alalayah et al., (2015) to culture Chlorella vulgaris sp at about 50, 100 and 120rpm stirring speeds in a modified stirred-tank photobioreactors (MSTPBRs) initially developed by Mohammed et al., (2014b); Mohammed, (2013) in order to assessed the Chlorella $v$ sp. growth rate in response to the varied stirring rates and subsequent other treatment and recovery processes

\section{MATERIALS AND METHODS}

\section{MSTPBR fabrication}

The 22L MSTPBR centrally illumination chamber was fabricated using a transparent plexiglas material (Globe Plastic Industries; Malaysia) of $9 \mathrm{~cm}$ in diameter and $25 \mathrm{~cm}$ depth housing a $2 \mathrm{~cm}$ diameter for stirrer shaft. The overall capacity of the MSTPBR was $32 \mathrm{cmX} 27 \mathrm{~cm}$ with a working volume of about $16 \mathrm{~L}$, which allowed about $30 \%$ headspace for degassing. Designed as semicontinuous reactor a tap was introduced at the bottom side of the MSTPBR for sample collection and mixing was provided using an overhead mechanical stirrer attached to an electric motor. Three MSTPBRs $R_{1}, R_{2}$ and $R_{3}$ were inoculated with $16 \mathrm{~L}$ of culture of microalgae and BBM solution to assessed the algal growth under different stirring rate

\section{Cultivation of algae}

The Chlorella v. sp. was obtained from Herbarium Laboratory, Department of Plant Biology, Bayero University Kano, Nigeria and cultivated in a $1 \mathrm{~L}$ Pyrex conical flask using Modified Bold Basal Medium (MBBM) in accordance with Alalayah et al., (2015), the composition of the mixture was shown in Table 1.cultured at about 280C and 
externally illuminated using cool white fluorescent tube (CTL-EL 102), for 8/16 light/dark photoperiod for 14days. All the chemicals used were of analytical grade purchased from Shumtech

\begin{tabular}{|c|c|c|c|}
\hline $\begin{array}{c}\mathrm{S} / \\
\mathrm{No}\end{array}$ & Formula & $\begin{array}{c}\text { Weigh } \\
\mathrm{t}(\mathrm{g})\end{array}$ & $\begin{array}{c}\text { Distil } \\
\text { Water } \\
\text { (L) }\end{array}$ \\
\hline 1 & $\mathrm{~K}_{2} \mathrm{HPO}_{4}$ & 1.875 & 250 \\
\hline 2 & $\mathrm{KH}_{2} \mathrm{PO}_{4}$ & 4.375 & 250 \\
\hline 3 & $\mathrm{MgSO}_{4} .7 \mathrm{H}_{2} \mathrm{O}$ & 1.875 & 250 \\
\hline 4 & $\mathrm{NaNO}_{3}$ & 6.250 & 250 \\
\hline 5 & $\mathrm{CaCl}_{2} \cdot 4 \mathrm{H}_{2} \mathrm{O}$ & 0.625 & 250 \\
\hline 6 & $\mathrm{NaCl}$ & 0.625 & 250 \\
\hline 7 & $\mathrm{Na}_{4}$ EDTA & 5.000 & 100 \\
\hline 8 & $\mathrm{KOH}$ & 3.100 & 100 \\
\hline 9 & $\mathrm{FeSO}_{4} .7 \mathrm{H}_{2} \mathrm{O}$ & 0.498 & 100 \\
\hline 10 & $\mathrm{H}_{3} \mathrm{BO}_{3}$ & 1.142 & 25 \\
\hline 11 & $\mathrm{MnCl}_{2} .4 \mathrm{H}_{2} \mathrm{O}$ & 0.058 & 25 \\
\hline 12 & $\mathrm{ZnSO}_{4} \cdot 7 \mathrm{H}_{2} \mathrm{O}$ & 0.353 & 25 \\
\hline 13 & $\mathrm{Co}(\mathrm{NO})_{2} .6 \mathrm{H}_{2} \mathrm{O}$ & 0.020 & 25 \\
\hline 14 & $\mathrm{Na}_{2} \mathrm{MoO}_{4} .2 \mathrm{H}_{2} \mathrm{O}$ & 0.048 & 25 \\
\hline
\end{tabular}

Scientific and Laboratory Supply, Kano, Nigeria

\section{Inoculum 1}

About $0.022 \mathrm{~g}$ of immobilized chlorella $v$. was weighed on an electronic weighing balance (ADAM : PW 214) and inoculated in a MBBM in a 1L Pyrex conical flask aerated using an air pump (haning Beach: SB660, China). This inoculated culture was externally illuminated by fluorescent bulb at 8/16 light and dark photoperiod for a period of 14days

\section{Inoculum 2}

The inoculum 1 was scaled-up and cultured in MBBM as previously described by Alalayah et al., (2015) in 22L MSTPBRs. The cultures in $R_{1}, R_{2}$ and $R_{3}$ were mixed thoroughly using an overhead mechanical stirrer at about 50, 100 and 120rpm respectively

Table 1: Composition of BBM

Alalayah et al., (2015)

\section{Illumination}

The reactors $R_{1}, R_{2}$ and $R_{3}$ were illuminated internally from the central core made of transparent Plexiglas, providing the light radially from the centre of the MSTPBRs by 189 red light emitting diodes (LEDs) (Kehong Opto Electronics, KH T542URC25-K, Guangdong, China) array on 9vero boards at an optimum irradiance of about $582.7 \mu \mathrm{mol} / \mathrm{m}^{2} \sin$ accordance with Mohammed et al., (2014b) from the central core to illuminate each of the $22 \mathrm{~L}$ reactors

\section{Experimental Set-up}

The MSTBRs $\left(\mathrm{R}_{1}, \mathrm{R}_{2}\right.$ and $\left.\mathrm{R}_{3}\right)$ as shown in Fig.1, were inoculated with culture medium (algal culture $+\mathrm{MBBM})$ to a working volume of $16 \mathrm{~L}$, illuminated to about an optimum irradiance of $582.7 \mu \mathrm{mol} / \mathrm{m}^{2} \mathrm{~s}$, at $12 / 12$ light-dark cycles.

The stirrers were set at an average speed of 50, 100 and $120 \mathrm{rpm}$ for $\mathrm{R}_{1}, \mathrm{R}_{2}$ and $\mathrm{R}_{3}$ respectively.

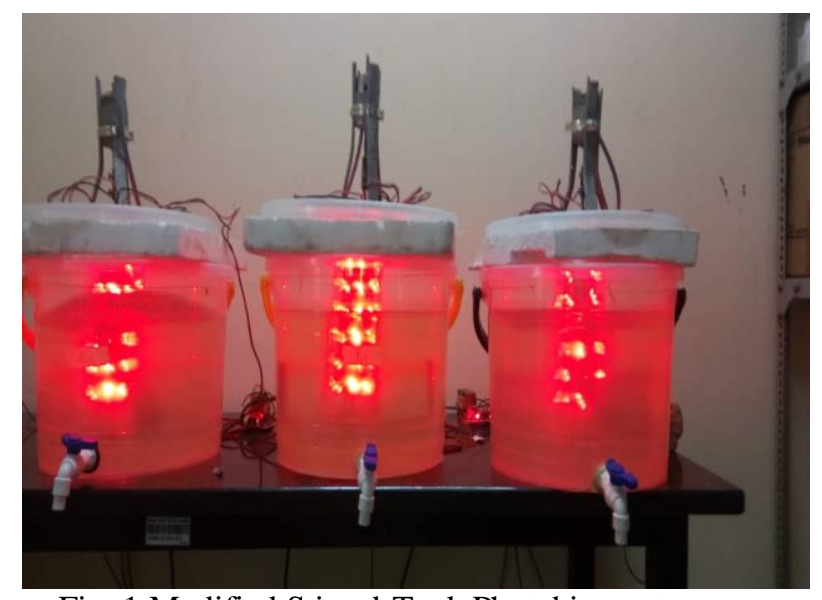

Fig. 1 Modified Stirred-Tank Photobioreactors MSTPBRs set-up

Aluminium foil was used to wrap the photobioreactors in order to minimize loss of light. The samples were collected at 2days interval for total suspended solids (TSS) analysis in accordance with Sun et al., (2019) in order to estimate the microalgal growth under the influence of varied stirring rate using Calorimeter, Hach: DR/890 series. The MBBM media was used as control and the $\mathrm{pH}$ of the culture was maintained at 7.2 using a $\mathrm{pH}$ meter and adjusted by hydrochloric $\mathrm{HCl}$ and sodium chloride ( $\mathrm{Nacl})$

\section{Estimation of Chlorella $v$. Concentration}

Both sample cell and cell compartment of the Colorimeter (Hach: DR/890) were cleaned with tissue paper and then, the programme number for TSS as 94 was selected and the media reagent solution was used to zero the instrument in which $25 \mathrm{ml}$ of the MBBM solution as blank was placed in 
the sample cell and with diamond-shaped marker toward the keypads, which was then rotated until it was aligned properly in the slot. The Colorimeter cap was used to cover the test compartment in order to shield against the external stray light and contributed to the accuracy of the result. The READ key was press and this was stored as zero reading and the Colorimeter was then ready for subsequent TSS measurements. Three samples from $\mathrm{R}_{1}, \mathrm{R}_{2}$ and $\mathrm{R}_{3}$ was prepared and shaken and then the placed in the sample cell compartment one after another for TSS as initially done for blank solution and the displayed results was recorded in $\mathrm{mg} / \mathrm{L}$.

\section{RESULTS}

The MBBM media was used as control to zero the calorimeter for the estimation of algal concentration as TSS and the initial TSS value after 2 weeks in inoculum 1 , was found to be $139 \mathrm{mg} / \mathrm{L}$ and this was subsequently diluted, up-scaled and cultured as inoculum 2 , in the three reactors with following concentrations at interval of 3days in table 2.

Table 2: Chlorella $v$. growth under different stirring rate

\begin{tabular}{|c|c|c|c|}
\hline \multirow{2}{*}{$\begin{array}{c}\text { Test } \\
\text { No. }\end{array}$} & \multicolumn{3}{|c|}{ Algal Concentration (mg/L) } \\
\cline { 2 - 4 } & R1(50rpm) & R2(100rpm) & R3(120rpm) \\
\hline Test 1 & 5 & 1 & 2 \\
\hline Test 2 & 20 & 26 & 9 \\
\hline Test 3 & 28 & 30 & 40 \\
\hline Test 4 & 33 & 34 & 49 \\
\hline Test 5 & 50 & 48 & 70 \\
\hline Test 6 & 65 & 105 & 86 \\
\hline Test 7 & 90 & 195 & 122 \\
\hline
\end{tabular}

From the result, it can be understood that in R1 with 50rpm stirring rate, the concentration of the biomass from an initial concentration of $5 \mathrm{mg} / \mathrm{L}$ to maximum attained as $90 \mathrm{mg} / \mathrm{L}$, within the first three weeks of chlorella vulgaris cultivation. The growth increases gently up to about 2 weeks of cultivation and after that a sharp increment was noticed. In R2, a more rigorous initial growth was obtained between first cultured concentrations of about $1 \mathrm{mg} / \mathrm{L}$ to as high as $26 \mathrm{mg} / \mathrm{L}$ within 3 days which increase rapidly up $195 \mathrm{mg} / \mathrm{L}$ for the span of 3weeks. R3 shows a moderate biomass concentration of until it reaches $9 \mathrm{mg} / \mathrm{L}$, after then a higher specific growth was noticed especially after the first week of cultivation which then maintained a moderate biomass growth within the reactor by the end of week three of the culture a concentration of $122 \mathrm{ml} / \mathrm{L}$ was observes.

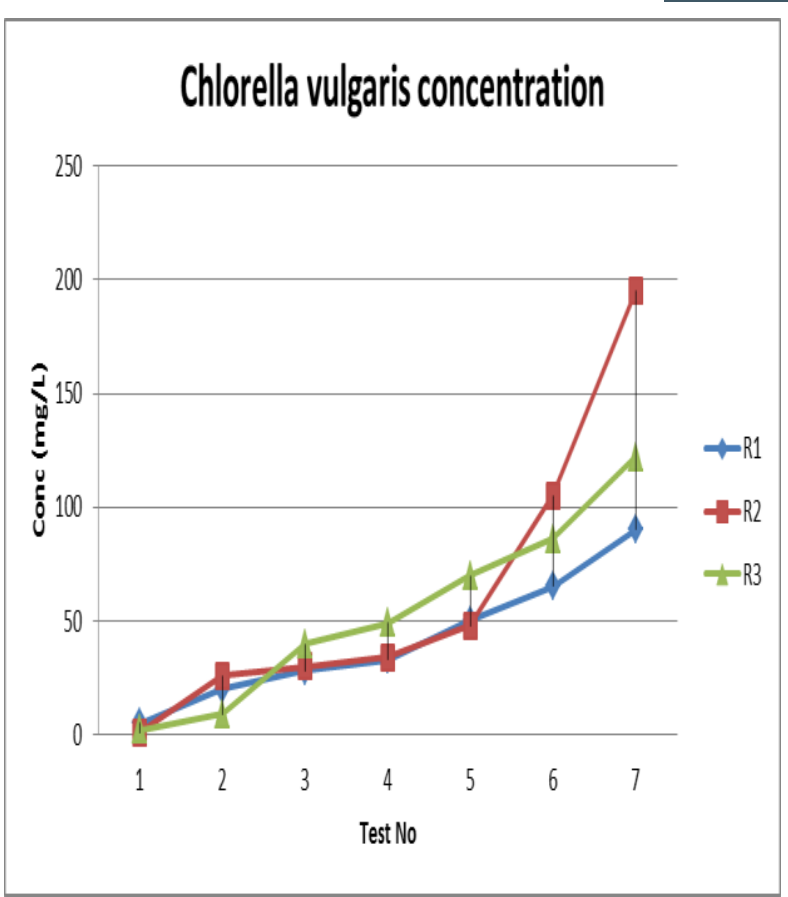

Fig. 2. Chlorella vulgaris growth within three weeks of cultivation

About $0.09,0.72$ and $0.14 \mathrm{~d}^{-1}$ growth rate was estimated in accordance with the approach reported by Arnas, (2014) and detailed interrelationship between the biomass concentrations of $R_{1}, R_{2}$ and $\mathrm{R}_{3}$ with their corresponding stirring rates could be clearly seen from Fig. 2.

\section{DISCUSSIONS}

Growth rate is one of the most crucial factors in understanding the level of adaptation to environmental conditions and succession of particular specie in the treatment medium or ecology. Extremely higher initial growth rates was obtained especially in $R_{2}$ and $R_{3}$ of 0.72 and $0.14 d^{-1}$ respectively, which were associated with higher stirring rates compared to that of $\mathrm{R} 1$ with low stirring rate. These growth rates was significantly higher than those reported by many researcher, Mohammed et al., (2014b) reported a relatively lower biomass growth rate and productivity of $0.109 \mathrm{~d}^{-1}$ and $0.034 \mathrm{gL}^{-1} \mathrm{~d}^{-1}$ despite the enhancement of $\mathrm{CO}_{2}$ supplementation to the cultures.

Priyadarshani et al., (2014) argued that the aeration and light not always proportional to the increasing the biomass growth as the specific growth rates under these conditions had no significant difference at 5\% confidence level. Mohammed et al., (2014b) hold a similar view on this as reported that the biomass growth was not always directly proportional to the irradiance provided to the culture and tested biomass productivity at irradiance of $429.9,582.7$ and $730.8 \mu \mathrm{mol} / \mathrm{m}^{2} \mathrm{~s}$ in a 
the highest growth was observed in the reactor with medium irradiance of $582.7 \mu \mathrm{mol} / \mathrm{m}^{2} \mathrm{~s}$. This can also be observed from current research in Fig.2, where despite the employment of various stirring rates of 50, 100 and $120 \mathrm{rpm}$ in the three MSTPBRs, there is no significant difference in the reactors especially within the first 10 days of the cultivation

During the first 12 days of the cultivation, none of the three culture growth above $50 \mathrm{mg} / \mathrm{L}$, and after then within the subsequent 9days the biomass growth reached $195 \mathrm{mg} / \mathrm{L}$. de la Noue et al., (1984) explained a related scenario in which during the first 3days of cultivation, the algal production continuous at about uniform rates in both cultures and then the biomass production seizes in the stirred cultures as $80-100 \mathrm{mg} / \mathrm{L}$ be significant as per as algal biomass growth and productivity is concerned was observed in the first 10days, while in aerated cultures increases daily by about $100 \mathrm{mg} / \mathrm{L}$ and after 10days of cultivation the biomass production reaches $700-750 \mathrm{mg} / \mathrm{L}$ which was found to

The biomass growth and productivity of the photosynthetic microorganisms increases with increment of turbulence induced by mechanical agitation (Pedruzi et al., 2020), this was noticed from Fig. 2 especially after the first 14days of the culture as the biomass concentrations in the $\mathrm{R}_{2}$ and $\mathrm{R}_{3}$ with their corresponding stirring rates of 100 and $120 \mathrm{rpm}$ respectively start to show significant increase than the $R_{1}$ with low stirring rates of 50rpm. This in line with the finding by de la Noue et al., (1984) that during first eight days of the cultivation, the biomass production seemed to be unaffected to the aeration rates and after that a considerable increase in biomass production was observed

The biomass concentration of R2 overtakes that of the R3 after about first 16days of cultivation and attained a higher productivity of about $195 \mathrm{mg} / \mathrm{L}$ with respect to that of $122 \mathrm{mg} / \mathrm{L}$ of $\mathrm{R} 3$ despite having higher stirring rate of $120 \mathrm{rpm}$, within the range of last 5 days of the test. This was found to be more interesting as initially perceived that the highest biomass productivities and growth rates should be directly proportional to the rate of stirring provided and that the other growth parameters like illumination culture medium, working volume and $\mathrm{pH}$ were kept constant.

Contrary to the above, increase in biomass production was reported by corresponding increase in the rate of stirring until a certain optimum level was reached and after that, a sharp declined of biomass concentration was observed (Pedruzi et al., 2020). Sobczuk et al., (2006) submitted that, the agitation by stirrer effectively improve the biomass production and increase in stirring rates up to the $350 \mathrm{rpm}$ that correspond to the stirrer's tip speed of $1.4 \mathrm{~m} / \mathrm{s}$ shows no sign of damage to the algal cells, but the damage of the hard protective cell wall of the eukaryotes was attributed not to stirring but sparging of gas at a speed above $1.5 \mathrm{~m} / \mathrm{s}$ of the stirrer's blades. As such a moderate stirring rate of about $120 \mathrm{rpm}$ should however, provide an optimum biomass concentration without hindrance, since it was not even near the maximum identified stirring rate of $350 \mathrm{rpm}$ that contribute to the decline in biomass growth and productivity.

However, despite the higher initial growth rates of the culture with about 15-fold, 25-fold and 7-fold of growth at $\mathrm{R}_{1}, \mathrm{R}_{2}$ and $\mathrm{R}_{3}$ respectively, a more closely monitoring of the treatment system will be provided in order to assessed the influence of stirring rates of $100 \mathrm{rpm}$ and $120 \mathrm{rpm}$ for R2 and R3 with their correspondence variations of biomass productivities especially with regards to the longer treatment period and the rate of biomass produced with its subsequent use for bioremediation process for sustainable wastewater treatment system at cost effective and production of energy alternatives such as biogas, biodiesel and other valuable materials.

\section{CONCLUSION}

Based on results of the investigation, it could be concluded that under optimum conditions of $\mathrm{pH}$, illumination and growth medium inoculated for 21days, the Chlorella vulgaris concentration in $\mathrm{R}_{1}$, $\mathrm{R}_{2}$ and $\mathrm{R}_{3}$ to be 90,195 and $122 \mathrm{mg} / \mathrm{L}$ at an average stirring rates of 50, 100 and $120 \mathrm{rpm}$ respectively. Also a higher initial growth rates for $\mathrm{R}_{1}, \mathrm{R}_{2}$ and $\mathrm{R}_{3}$ was estimated to be $0.09,0.72$ and $0.14 \mathrm{~d}^{-1}$ respectively.

\section{ACKNOWLEDGEMENT}

The efforts of Dr Kasim Mohammed of Civil Engineering Department, Bayero University Kano, M. Bahaudden of Herbarium Laboratory, Department of Plant Biology, Bayero University Kano and The Engr. Zubairu Garba, Mr Auwal Musa and Mudassir Y. I. of Tamburawa Water Treatment for their assistance in obtaining the Chlorella sp., culturing and monitoring of the growth was highly acknowledged and appreciated. 


\section{REFERENCES}

1. Agarwal, P., Gupta, R., \& Agarwal, N. (2019). Advances in Synthesis and Applications of Microalgal Nanoparticles for Wastewater Treatment. Journal of Nanotechnology, (pp1-9). https://doi.org/10.1155/2019/7392713

2. Al-Shatri, A. H., Ali, E., Al-Shorgani N. K. N., and K. M. K. (2014). Growth of Scenedesmus dimorphus in different algal media and $\mathrm{pH}$ profile due to secreted metabolites. African Journal of Biotechnology, 13(16), (pp1714-1720). https://doi.org/10.5897/AJB2013.13455

3. Alalayah W. M., Yahia A. A., Al-Zahrani, A., and Edris, G. (2015). Experimental Investigation Parameters of Hydrogen Production by Algae. International Conference on Chemical, Environment \& Biological Sciences, (September 2014), (pp41-43).

https://doi.org/http://dx.doi.org/10.15242/IIC BE.C914010

4. Arnas, S. (2014). Cultivating Algae in a Photobioreactor: Synthetic wastewater nutrient removal and carbon capture efficiency using the green algae species Chlorella pyrenoidosa. Thesis Helsinki Metropolia University of Applied Sciences. (pp. 1-38)

5. Benítez, M. B., Champagne, P., Ramos, A., Torres, A. F., Ochoa-herrera, V., Belén, M., ... Benítez, M. B. (2018). Wastewater treatment for nutrient removal with Ecuadorian native microalgae. Environmental Technology, (pp1-9). https://doi.org/10.1080/09593330.2018.14598 74

6. Sobczuk F. M., Camacho E. G., Grima M and Chisti Y. (2006). Effects of agitation on the microalgae Phaeodactylum tricornutum and Porphyridium cruentum. Bioprocess Biosyst Eng, 28, 243250. https://doi.org/10.1007/s00449-005-0030-3

7. Fu, F., \& Wang, Q. (2011). Removal of heavy metal ions from wastewaters: a review. Journal of Environmental Management, 92(3), (pp407-418). https://doi.org/10.1016/j.jenvman.2010.11.01 1

8. García, D., Alcántara, C., Blanco, S., Pérez, R., Bolado, S., \& Muñoz, R. (2017). Enhanced carbon, nitrogen and phosphorus removal from domestic wastewater in a novel anoxic-aerobic photobioreactor coupled with biogas upgrading. Chemical Engineering Journal, $\quad 313, \quad$ (pp424-434). https://doi.org/10.1016/j.cej.2016.12.054

9. de la Notie, J., Cloutier-Mantha, L., Walsh, P and Picard, G. (1984). Influence of Agitation and Aeration Modes on Biomass Production by Oocystis $\mathrm{sp}$. Grown on Wastewaters. Biomass, 4, (pp43-58).

10. Komolafe, O., Velasquez, S., \& Monje, I. (2013). Biodiesel production from indigenous microalgae grown in wastewater. https://doi.org/10.1016/j.biortech.2013.12.048

11. Mohammed et al., 2014a. (2014a). Energyefficient stirred-tank photobioreactors for simultaneous carbon capture and municipal wastewater treatment. Water Science \& Technology, 69(10), (pp2106-2112). https://doi.org/10.2166/wst.2014.123

12. Mohammed, K. (2013). Microalgal Photobioreactors for Carbon-Efficient Wastewater Treatment. Thesis. Newcastle University. (pp. 1-157)

13. Mohammed, K., Ahammad, Z. S., Sallis, P. J., \& Mota, C. R. (2014b). Optimisation of red light-emitting diodes irradiance for illuminating mixed microalgal culture to treat municipal wastewater. Transactions on Ecology and The Environment, 178, (pp263270).

14. Mustafa, S. M., Chua L. S and El-Enshasy, H. A. (2019). molecules E ff ects of Agitation Speed and Kinetic Studies on Probiotication of Pomegranate Juice with Lactobacillus casei. Molecules, 24(2357), (pp1-13).

15. Pathak, V. V, Ahmad, S., \& Kothari, R. (2019). Implication of Algal Microbiology for Wastewater Treatment and Bioenergy Production. Environmental Biotechnology for Sustainable $\quad$ Future, (pp1-24). https://doi.org/http://doi.org/10.1007978-98110-7284_10

16. Pedruzi, G. O. L., Amorim, M. L., Santos, R. R., Martins, M. A., \& Vaz, M. G. M. V. (2020). Biomass accumulation-influencing factors in microalgae farms em fazendas de microalgas. Revista Brasileira de Engenharia Agrícolae Ambiental, 24(2), (pp134-139). https://doi.org/http://dx.doi.org/10.1590/18071929/agriambi.v24n2p134-139

17. Priyadarshani, I., Thajuddin, N., \& Rath, B. (2014). Influence of aeration and light on biomass production and protein content of four species of marine Cyanobacteria. International Journal of Current Microbiology and Applied Sciences, 3(12), (pp173-182).

18. Sun, L., Zuo, W., Tian, Y., Zhang, J., Liu, J., Sun, N., \& Li, J. (2019). Performance and microbial community analysis of an algalactivated sludge symbiotic system : Effect of 
International Journal of Engineering Applied Sciences and Technology, 2020

Vol. 4, Issue 11, ISSN No. 2455-2143, Pages 454-460

Published Online March 2020 in IJEAST (http://www.ijeast.com)

activated sludge concentration. Journal of Environmental Sciences, 76.

19. Xie et al., 2017. (2017). Microalgal Cultivation in Secondary Effluent: Recent Developments and Future Work.
International Journal of Molecular Sciences, 18(79), (pp1-18). 